The pages which deal with diseases of the Nervous System might be taken as having the stamp of authority, the writer being himself a Neurologist of standing; but even here information is meagre and technical detail of treatment, one of the most important therapeutic problems of Short-Wave, almost entirely non-existent.

\section{AN EPITOME OF THE LABORATORY DIAGNOSIS AND TREATMENT OF TROPICAL DISEASES.}

By Horace M. Shelley.

John Bale \& Sons \& Danielsson Ltd., 83-91 Great Tichfield Street, W.1. 1936. Price 2/6.

This little book is intended to give information to the practitioner in the tropics about the laboratory diagnosis and treatment of tropical diseases. It answers the questions when and how can the laboratory be useful to the physician in the tropics. In the case of some of the diagnostic procedures, such as those for blood diseases, the descriptions are long enough to be a guide to the actual performance of the tests. It is doubtful, however, if the description of other tests, such as those for bacterial or helminth infections, are sufficiently detailed to be of practical value. The book would be useful to post-graduate students of medicine who are looking for a brief introduction to tropical medicine.

\section{RECENT ADVANCES IN DERMATOLOGY.}

By W. N. Goldsmith. J. \& A. Churchill, Ltd. London. 1936. Price 18/-.

"Recent Advances In Dermatology" is a valuable addition to a useful series of books, and will be gratefully received by all interested in diseases of the skin. In his preface the author modestly claims that the value of his book has been largely to himself in the writing of it, but its perusal leaves no doubt that it will be of equal value to its readers.

During the last quarter of a century great developments have taken place in various branches of medicine which have an intimate bearing on the causation of skin diseases, such as in bio-chemistry, psychology, and endocrinology. The important researches of Sir Thomas Lewis on histamine and allied bodies, and on the structure of the cutaneous capillaries have shed new light on the pathogenesis of urticaria and other cutaneous reactions. The study of the reticulo-endothelial system and the metabolism of lipoids have paved the way to a better understanding of xanthoma and allied conditions. Our knowledge regarding the problems of immunology and allergy has been enlarged and crystallised. These and other advances have so reacted on dermatology as to make it a more complex study and so to increase the literature relating to it as to render a book such as this not only timely but essential.

The initial chapters are concerned with the blood vessels, skin glands and pigmentation; these are followed by sections on the disorders of metabolism and the influence of the nervous and endocrine system on the causation of skin diseases; among others as an increase of progress is a chapter on affections due to filterpassing viruses which includes herpes zoster, warts, molluscum contagiosum, and without sufficient proof pityriasis rosea.

The book is of value not only as indicating the directions in which our knowledge has advanced, but also those in which it is lacking and where further observation and research are needed. We find to our disappointment that we are still undecided as to the etiology of psoriasis, pityriasis rosea and even lupus erythematosus.

The book is clearly and concisely written. It might be objected that here and there it presumes a too intimate knowledge of work such as that of Sir Thomas Lewis, but that indirectly is an asset should it act as a stimulant to a closer study of such important work.

Printed on good paper, sufficiently illustrated by coloured plates and figures in the text, with an extensive bibliography appended to each section, it cannot but be a welcome addition to the library of every dermatologist. It is only those who have undertaken work of this kind who can appreciate the immense labour which it has entailed and the author is to be congratulated on the successful accomplishment of an arduous task. 